\title{
A infância pobre e sua assistência no século XX
}

\author{
Kilza Fernanda Moreira de Viveiros *
}

Resumo. Este estudo se constitui como parte das análises desenvolvidas sobre a infância e a criança durante o nosso processo de formação doutoral, que discorre sobre práticas de educação sócio-educativas em São Luís do Maranhão, Brasil. Assim objetivamos conhecer os sentidos da infância, suas concepções, seus cuidados, assistência e sua educação não escolar durante as primeiras décadas do século XX no Maranhão. Para tanto ressaltamos que as nossas observações se construíram teórico metodologicamente com base na literatura internacional, nacional, local, dando privilégio às fontes documentais com a utilização de um periódico de época. Considerando as singularidades locais, vale dizer que este estudo se sustenta em abordagens teóricas da história social da infância, associadas à compreensão das concepções de higienismo e eugenia, que subsidiam metodologicamente a análise das fontes documentais. Assim, nosso estudo evidencia a importância da criação de instituições assistencialistas sócio-educativas, bem como a articulação de suas finalidades, ao projeto republicano de progresso urbanização e modernização do Brasil.

Palavras-chave: Assistência; pobreza; infância.

\section{LA INFANCIA POBRE Y SU ASISTENCIA EN EL SIGLO XX}

Resumen. Este estudio se constituye como parte de los análisis desarrollados sobre la infancia y los niños durante nuestro proceso de formación doctoral, que se centra en las prácticas socioeducativas de educación en San Luis de Maranhao, Brasil. De esta forma, buscamos conocer los sentidos de la infancia, sus concepciones, sus cuidados, su asistencia y su educación no escolar durante las primeras décadas del siglo XX en Maranhao. Para ello hacemos hincapié en que nuestras observaciones se construyeron teórica y metodológicamente basadas en la literatura internacional, nacional y local, prestando mayor atención a las fuentes documentales con la utilización de un periódico de época. Teniendo en cuenta las singularidades locales, cabe mencionar que este estudio se basa en enfoques teóricos de la historia social de la infancia, asociados a la comprensión de las concepciones de higienismo y eugenesia, que subsidian metodológicamente el análisis de las fuentes documentales. Por lo tanto, nuestro estudio pone de relieve la importancia de la creación de instituciones asistencialistas socio-educativas, así como la articulación de sus finalidades, al proyecto republicano de progreso, urbanización y modernización de Brasil.

Palabras clave: Asistencia; pobreza; infancia.

* Universidade Federal do Rio Grande do Norte (UFRN), Brasil. 


\begin{abstract}
POOR CHILDHOOD AND ITS ASSISTANCE IN THE TWENTIETH CENTURY
Abstract. This study is constituted as part of the analyzes carried out on childhood and child during our doctoral training process, which discusses socio-educational education practices in Sao Luis, Brazil. So we aim to meet the children's senses, their views, their care, their care and no education during the first decades of the twentieth century in Maranhao. Therefore we emphasize that our observations were built theoretical methodologically based on international literature, national, local, giving privilege to documentary sources with the use of a regular season. Considering the local singularities, that is to say that this study is based on theoretical approaches to the social history of childhood, associated with the understanding of the concepts of hygienism and eugenics, which methodologically subsidize the analysis of documentary sources. Thus, our study highlights the importance of creating social and educational welfare institutions, as well as the articulation of its purposes, the Republican progress project, urbanization and modernization of Brazil.
\end{abstract}

Keywords: Assistance; poverty; childhood

Este estudo se constitui como parte das análises desenvolvidas sobre a infância e a criança durante o nosso processo de formação doutoral, que discorre sobre práticas de educação sócio-educativas em São Luís do Maranhão, Brasil. Assim objetivamos conhecer os sentidos da infância, suas concepções, seus cuidados, assistência e sua educação não escolar durante as primeiras décadas do século XX no Maranhão. Para tanto ressaltamos que as nossas observações se construíram teórico metodologicamente com base na literatura internacional, nacional, local, dando privilégio às fontes documentais com a utilização de um periódico de época.

Considerando as singularidades locais, vale dizer que este estudo se sustenta em abordagens teóricas da história social da infância, associadas à compreensão das concepções de higienismo e eugenia, que subsidiam metodologicamente a análise das fontes documentais. Assim, nosso estudo evidencia a importância da criação de instituições assistencialistas sócioeducativas, bem como a articulação de suas finalidades, ao projeto republicano de progresso, urbanização e modernização do Brasil.

Entre as preocupações que marcam o início do século XX no Brasil diz respeito à infância, denunciada pelos médicos, juristas, educadores e jornalistas. Um grande número de crianças morria açoitado ${ }^{1}$ pelas epidemias e ausência de condições de higiene física e moral nos aglomerados urbanos. Porém, o que chamava a atenção dessa elite era as estatísticas criminais

1 Aqui, a palavra açoitada assume o significado de flagelo. 
(Rizzini, 1993, p. 25), levantando a possibilidade de estarem as crianças correndo riscos ou de serem elas responsáveis por colocar a sociedade em situação de perigo.

Essa preocupação com a infância do início dos novecentos estava relacionada ao projeto de normalização da sociedade, que apontava crescimento desordenado de crianças em situação de pobreza e graças aos problemas sociais advindos antes da transição do Império para a República, como a abolição da escravatura.

No entanto, as medidas tomadas para reparar a ordem e adequar a sociedade brasileira ao modelo europeu implicaram uma série de intervenções autoritárias à população, como foi o caso da vacinação obrigatória nas grandes cidades contra a varíola, além do combate aos focos do mosquito transmissor da febre amarela.

Com a expansão desordenada das cidades, criaram novas necessidades de organização social em que o Estado, associado ao saber médico, buscava maneiras de intervenção sanitária e assistencial, porém prevalecendo a função de policiamento sanitário em detrimento da assistência pública. Vale salientar ainda que essas medidas sanitárias preventivas, ao contrário das de assistência, reuniam recursos e atenção em todo território brasileiro.

Nessa ótica, as crianças abandonadas ou pobres, alvo da assistência, "[...] vagavam pelas ruas das principais cidades, como Rio de Janeiro, São Paulo e Salvador em busca da sobrevivência, quadro que também se desenhava em São Luís do Maranhão". (Lima, 1951, p. 88).

Às crianças pobres, programas de assistência se constituíam em dispensários, tratamento e profilaxia das doenças, creches e distribuição de gêneros de primeira necessidade. "Ao menor abandonado e delinquente, estavam reservados o asilo preventivo e o asilo reformatório". (Rizzini, 1993, p. 25). Entretanto, a participação do Estado na assistência era vista como insignificante, apenas se consolidando nos anos de 1920 com a criação do Juízo de Menores e a promulgação do primeiro Código de Menores.

No entanto, a preocupação com as crianças nas ruas, nos asilos, nas famílias, nas fábricas, com a mortalidade e a criminalidade continuavam a ser foco de olhares, tendo em vista a necessidade de criação de medidas que viessem a proteger e a assistir à infância desvalida, como que também pudessem "[...] aliviar a consciência de uma sociedade envergonhada e ameaçada com a sua presença”. (Rizzini, 1993, p. 26). 
A compreensão de criança desvalida perpassa a concepção daquele "[...] que não possui valor, encontra-se desprotegido, desamparado, desgraçado, miserável". (Dicionário Aurélio, 1998. p. 352). No entanto, o Dicionário da Língua Portuguesa (1927) define desvalido como "desprotegido, desamparado, pobre, desgraçado, e desvalimento, falta ou perda de favor, de proteção, de valimento". Então, observamos que tal significado se assemelha em dicionários do século XIX e início do século XX.

Mais que um significado, a criança desvalida legitimava o descaso social no Brasil se fazendo representar nas ruas das grandes cidades com aparência desnutrida, usando poucas vestes e com aspecto doentio. essas crianças carregavam no olhar a falta de perspectiva de vida futura.

Dada essa compreensão, a infância desvalida e maltratada tomou assento nas denúncias médicas nas classes desafortunadas. De acordo com Moncorvo Filho (1926, p. 35), o problema era originário da ignorância dos pais "[...] dos mais rudimentares preceitos da higiene [...]", levando os filhos a consumirem álcool, drogas como o ópio, além alimentos inadequados em todas as idades.

Esse consumo atendia a diversas finalidades, de acordo com os serviços clínicos de ambulatório nos Institutos de Assistência e Proteção à Infância do Rio de Janeiro. 0 álcool - vinho e aguardente -, segundo os pais, servia aos filhos como fortificante ou calmante. Prática semelhante percebemos no relatório do Instituto de Proteção à Infância de Lisboa, onde a criança bebia sopa de vinho antes de ir para o campo, no entanto do sentido cultural do consumo da bebida alcoólica se associava à obtenção de força para o trabalho no campo.

O ópio e a alimentação inadequada também se evidenciam nos relatos do instituto. 0 ópio era utilizado para prolongar o sono das crianças, fazendo com as mães pudessem descansar por horas. No que se refere à alimentação inadequada, registraram-se na dieta alimentar das crianças, incluindo as de menor idade, angu, peixe, feijão, arroz e carne seca. (Moncorvo Filho, 1914, p. 40).

Entretanto, não só o uso de álcool, ópio e má alimentação faziam parte dos registros ambulatoriais. Havia um bom número de crianças que buscava cuidados médicos devido à violência doméstica e castigos cruéis, como exposição à chuva e ao frio, bem como espancamentos com os mais variados objetos. 
Do ponto de vista médico, outra preocupação se assolava. As crianças internadas nos asilos, devido à falta de condições de higiene nesses locais, eram acometidas de viroses e doenças, o que aumentava as taxas de enfermidade e mortalidade infantil.

Essa preocupação trazia a debate da defesa ou não desses asilos e sua eficácia na prevenção da criminalidade pelas autoridades, porém o caráter disciplinador dessas instituições se tornou a tônica do discurso jurista à situação do menor moralmente abandonado, tendo em vista representar uma ameaça social.

Entretanto, essa ameaça social se entrelaçava à preocupação médica expressada nas palavras de Moncorvo Filho (1926, p. 132), quando diz: "Quantas crianças temos nós encontrado, isoladas ou em maltas, seminuas, sórdidas, maltrapilhas [...]. Acordadas ou deitadas, durante o dia, no limiar das casas particulares? [...]. A dormirem a noite nas escadarias dos edifícios públicos [...]".

O quadro descrito acima foi capaz de provocar sentimentos e atitudes reveladores de posicionamentos sociais, científicos e políticos, os quais demarcam uma época em que civilizar a sociedade era sinônimo de eliminar as ameaças representadas pelas condições de vida insalubre.

Nesse âmbito, a criança desvalida (o menor moral e materialmente abandonado nos centros urbanos) concebia um perfil de sociedade não civilizada. A situação de pobreza originária de problemas que não eram privilégio da República era perceptível na medida em que a essa infância faltavam medidas eficazes e de responsabilidade pública.

Essas medidas, porém, eram muito mais atenuadas como mantenedoras de uma ordem imposta pelos preceitos republicanos ${ }^{2}$ do que numa dimensão educativa. Assim, a preocupação com a infância, sobretudo pobre, recaía como meio de reconhecimento social a diversos segmentos políticos.

Nessa ótica, construir uma ordem social com base nos preceitos republicanos atenuava os aspectos da pobreza. "Apesar da miséria, os pobres são iguais na medida em que participam do mesmo estatuto jurídico dos demais cidadãos" (Beghin, 2005, p. 43); nesse segmento, a igualdade nos leva a refletir a pobreza como questão social, adentrando um espaço de discussões políticas e de direitos. No entanto, percebemos que os pobres de que falamos neste trabalho, ou seja, as crianças em situação de miséria,

2 Para a autora, são considerados preceitos republicanos de uma ordem social as bases individualistas de liberdade e igualdade, afirmando a soberania do indivíduo. 
desvalimento ${ }^{3}$, apresentavam-se esvaziadas da sua dimensão política, sendo interpretadas como problema moral capaz de associar interesses particulares, ou de pequenos grupos, ao interesse geral.

Na medida em que a pobreza da criança brasileira, particularmente a maranhense, passou a ser o centro de discussões e medidas de um grupo da elite, .tendendo à sua socialização, percebemos práticas implicadas no poder. Nessa perspectiva, o social se configurava como espaço político resultante de um projeto de alcance maior. Vale acrescentar que o grupo a que nos referimos era representado pelos militares, médicos, políticos, juristas, escritores e jornalistas, entre outros que exerciam algum tipo de poder sobre a sociedade.

Sendo a criança uma construção cultural, resultado de práticas e representações (Chartier, 1990) pontuadas num determinado tempo e espaço, faz-se necessário, neste trabalho, compreender os sentidos da pobreza ${ }^{4}$ nas primeiras décadas do século XX, a fim de tecermos as relações da criança pobre com os exercícios de filantropia na sociedade brasileira e maranhense.

Etimologicamente, a palavra pobre/pobreza origina-se no latim e tem seu significado associado a terrenos agrícolas, que produziam aquilo que não era desejado ou eram considerados inférteis. (Dicionário da Língua Portuguesa, 2005, p. 1180). Com a evolução das sociedades, sua empregabilidade assumiu novos sentidos, porém sempre relacionados a alguma coisa não almejada.

Entre os seus vários significados, destacamos essencialmente dois: aqueles relacionados à falta de alimentação, moradia, cuidados com a saúde; e os referentes à incapacidade de participação na vida social, incluindo a falta de educação escolar, de informação, de acesso à cultura, em seu significado amplo. Nessa perspectiva, o primeiro sentido pode ser entendido como um estado de carência de bens essenciais e o segundo, como carência social.

Apesar de essas duas denominações estarem relacionadas à riqueza, a noção de pobreza conota de forma negativa, implicando uma condição vil, frágil, podendo assumir o sentido popular daquele que precisa de algo.

${ }^{3}$ Sem valor. Vai originar na utilização da terminologia criança desvalida utilizada pelos jornais de época na sociedade maranhense, como criança sem valor, desprotegida, desprovida de cuidados.

4 Terminologia utilizada pela autora para expressar o significado do vocábulo em nível da carência material e social. 
De acordo com o dicionário da língua portuguesa (Michaelis, 2002, p. 610), a palavra pobre significa também desprotegido, digno de compaixão - indigência, miséria, penúria.

Quando falamos de pobreza, sempre perpassa a ideia de que a miséria é uma coisa e a pobreza é outra. Entretanto, é importante compreender que, segundo Fonseca (1935), a miséria é um aspecto integrante da condição humana, resultante de um fenômeno natural e inevitável como é a desigualdade, que, segundo o mesmo autor, é outro aspecto importante na definição de pobreza. Se a pobreza é condição natural e inevitável, jamais se extinguirá de que é um aspecto das sociedades e suas condições de vida material e social. Porém, o termo indica sentimentos e atitudes, como compaixão, medo, desprezo e até piedade.

Apesar de compreendermos a miséria como uma circunstância da pobreza que inspira indigência, penúria e estado indigno, esta esteve sempre relacionada às práticas das igrejas cristãs que, através de suas obras caritativas, devolviam às pessoas chamadas pobres a dignidade e a melhoria social.

Entretanto, é preciso ampliar a noção de pobreza, fenômeno geralmente associado a fatores econômicos das sociedades contemporâneas, mas que sempre esteve presente na humanidade, podendo sua explicação através dessa via nos trazer uma noção limitada ao propósito deste trabalho.

É necessário perceber a pobreza de maneira interdisciplinar, fazendo ligações entre a ordem vigente e sua temporalidade, conhecer a sociedade de que falamos da pobreza, quem eram considerados pobres e em que condições de vida material e social viviam, além de perceber a quem a pobreza chamava a atenção e com que finalidade política ela deveria permanecer ou não.

Outro elemento importante associado à pobreza é o fenômeno do "[...] pauperismo, forma mais dramática da pobreza que supõe a sobrevivência de alguns dependentes do auxílio do outro ou da assistência pública". (Fernandes; Vidigal, 2005, p. 72).

A partir dessa compreensão, devemos pensar a criança pobre brasileira e maranhense do início dos anos 1900 como aquela que necessitava sobreviver às transformações impostas pelo novo ordenamento através de ações que viessem a favorecê-la não apenas em seu aspecto material, mas também social. 
Pensar essa criança nos conduziu, também, ao entendimento sobre o que realmente a sociedade política e intelectual queria dela. Cuidar de seus surtos epidêmicos, saneá-la, educá-la para ser uma nova nação ou livrar-se de seu convívio ameaçador?

Associar essa criança às suas condições de miséria nos remeteu a práticas de assistência que se desenvolveram através de instituições sociais, como a Confraria da Misericórdia de Portugal fundada em 1498 pela rainha Leonor de Lancastre, a Santa Casa de Misericórdia do Rio de Janeiro, fundada pelo Padre Anchieta em 1553, e o Hospital da Santa Casa de Misericórdia do Maranhão, fundada pela Irmandade da Misericórdia em 1653.

A rainha $\mathrm{D}$. Leonor de Lancastre, viúva do rei D. João II, instituiu uma irmandade de invocação a Nossa Senhora da Misericórdia, na capela de Nossa Senhora da Piedade, no ano em que os navegadores portugueses chegaram à Índia, completando quase um século de navegação e em devoção e agradecimento a Nossa Senhora, a confraria seria orientada por princípios estabelecidos no compromisso com a misericórdia. A Santa Casa da Misericórdia do Rio de Janeiro era considerada pela Igreja um prolongamento da Confraria da Misericórdia de Lisboa.

Já o Hospital da Santa Casa de Misericórdia do Maranhão foi instalado em 1653, por iniciativa da Irmandade da Misericórdia, dos jesuítas, tendo à frente o padre Antonio Vieira (Meireles, 1994). Funcionava em imóvel alugado, pois foram em vão os esforços para a sua construção, "[...] embora a obra não fosse adiante, conseguiu sempre que se dispusesse uma casa particular para receber os enfermos". (Lisboa, 1864, p. 209). Sua sede própria e definitiva, na Rua do Norte em São Luís, só foi inaugurada no dia 19 de março de 1814, cento e sessenta e um anos após a benemérita iniciativa do Padre Vieira, com a denominação de Hospital de São José da Santa Casa de Misericórdia. Assistência emocional para a autora representa toda prática de assistência determinada por sentimentos piedosos.

À exemplo dessas instituições é importante observarmos que a concepção de pobreza "[...] já se encontrava secularizada [...]" (Kuhlmann Júnior, 1998, p. 59) e abraçada pela caridade das ações religiosas. Com isso, percebemos que a caridade 
[...] relaciona-se a um período anterior e assumiu significados diferentes ao longo da história, referindo-se à religião, ao Estado, ou a um sentimento de ordem individual em relação à pobreza. 0 mesmo ocorreu com a palavra filantropia que pode se referir à secularização, à iniciativa não governamental, ou à organização racional da assistência. (Kuhlmann Júnior, 1998, p. 60).

Mediante tais denominações, observamos através dos discursos jornalísticos sobre a Assistência à Infância do Maranhão o modelo de assistência de caráter filantrópico, compatível com a prestação de serviços através do saber médico, bem como a organização racional da assistência em substituição à assistência emocional ${ }^{5}$.

No que se refere ao binômio caridade e filantropia, podemos dizer que através das atividades lideradas pelas Damas da Assistência tivemos o indicativo de aproximação dos diferentes conceitos assistenciais, não sendo possível perceber o instituto como protagonista de atividades somente filantrópicas, como diziam os médicos.

As Damas da Assistência eram senhoras da elite maranhense, esposas de médicos higienistas, jornalistas, militares e advogados que organizavam atividades sociais de cunho assistencialistas a fim de que outras pessoas da sociedade participassem e assumissem a causa da pobreza infantil como ação política.

Sobre a perspectiva da prática assistencialista do instituto, observamos o grande alcance social a partir da aplicação do saber médico e do cumprimento dos ideais republicanos através do higienismo e da medicina social.

Nessa perspectiva, também, percebemos a comparação entre a utilização das palavras caridade e filantropia, evidenciando um polo de discussão entre suas ações, dando relevância à filantropia como organização racional da assistência. Entretanto, segundo Rizzini (1993, p. 48), “[...] a caridade e a filantropia apresentavam o mesmo objetivo, que vinha a ser a proteção da ordem social [...]".

A luta de forças entre a caridade e a filantropia foi antes de tudo uma disputa política e econômica pela dominação sobre o pobre. A pobreza, até o século XIX, pertencia ao domínio absoluto da Igreja. A preocupação com a pobreza por parte das ciências, como a medicina, a economia, a sociologia, a pedagogia, e outras, permitiu tomarem pra si diversos aspectos

5 Assistência emocional para a autora representa toda prática de assistência determinada por sentimentos piedosos. 
do pauperismo como objetos de estudo. Desta forma fornecem às elites sociais e políticas os instrumentos que possibilitaram-nas reclamar para si o domínio de uma situação que as ameaçava diretamente e que a Igreja mostrava-se incapaz de controlar. (RIZZINI, 1993, p. 48).

Assim, a filantropia emergiu fundamentada pela ciência com a finalidade de organizar a assistência de acordo com as necessidades sociais, políticas, econômicas e morais, as quais vieram com o advento da República.

Apesar de sua raiz humanitária ${ }^{6}$, a filantropia foi se solidificando, desde os primórdios do liberalismo ${ }^{7}$, mas possui uma base na sensibilidade moral como modo de aproximar a miséria e a ordem. "Com isso, a filantropia elabora, pragmaticamente, uma referência ao interesse coletivo, de natureza essencialmente moral, que é o de reduzir a miséria e o perigo social que ela representa". (Beghin, 2005, p. 45).

Com práticas que promoveram a fusão entre o interesse individual, ou de grupos, e o interesse geral, a filantropia possibilitava ações que não interferiam nos interesses da ordem, ao contrário, ajudavam a minimizar o papel do Estado 8 em relação à pobreza. Nessa vertente, percebemos, através das práticas filantrópicas no Maranhão, a preocupação da sociedade que a praticava em preservar a imagem da capital limpa das mazelas causadas pelo pauperismo.

Apesar de o Maranhão não ter tido nenhuma junta republicana e sendo o Estado mais ligado a Portugal do que ao Brasil durante o período imperial, a preocupação sanitária assolava a sociedade e práticas caritativas já se desenvolviam antes do advento da República.

Percebemos nos textos do jornal A Pacotilha, já nos 1910, um ano antes da fundação do Instituto de Assistência à Infância, ações beneficentes que não estavam somente sob o interesse da igreja, mas, sobretudo, relacionadas ao interesse de determinada camada da sociedade, assumindo o caráter filantropo em detrimento da caridade.

${ }^{6}$ Etimologicamente, a palavra filantropia origina-se do grego, em que philos quer dizer amor e antropos, homem, ou seja, amor do homem pelo ser humano, amor pela humanidade. (Beghin, 2005, p. 45).

7 Liberalismo como um sistema de dominação. (Beghin, 2005, p. 45).

${ }^{8}$ Estado "[...] significa conjunto de poderes políticos de uma nação, nação politicamente organizado por leis próprias”. (Dicionário da Língua Portuguesa, 2005, p. 653). 
Muitas dessas manifestações ganharam força na medida em que a infância pobre tomava as páginas desse periódico como forma de chamar a atenção para os perigos dela decorrente. Entretanto, como a pobreza se constituía um perigo ao futuro, o problema da criança pobre trazia à sociedade preocupações que determinariam o apoio à constituição de um instituto que viesse cuidar da problemática.

Desse modo, o movimento aderido pelo jornal A Pacotilha sobre a infância desvalida ganhou força e adeptos. Através do discurso médicohigienista, somaram-se novos esforços sociais, pontuando a finalidade de cuidar das crianças em situação de pobreza.

Com a libertação do cativeiro negro, muitas crianças andavam pela capital maranhense sem vestes, descalças e sem nenhuma forma de acolhimento social, como, por exemplo, ser educada em escolas ou asilos.

Então as campanhas através do campo médico social se direcionaram não apenas a essa criança, mas apontavam também preocupações com a mulher, sendo esta a mãe das crianças desvalidas e suas condições de vida.

Nesse percurso, também era foco de atenção o controle à natalidade, o acompanhamento da gravidez e do nascituro, controle de doenças venéreas e doenças de ordem degenerativas, como as pestes, a lepra, entre outras enfermidades.

Com a intenção de afastar a criança de um ambiente sócio-familiar conturbado, circundado por alcoolismo, prostituição, criminalidade e vida insalubre, os médicos higienistas maranhenses, com apoio social dado à repercussão das matérias jornalísticas, organizam modos de atendimento doméstico e domiciliar, a fim de cuidar da infância pobre, mas apontando, também, evidenciarem, reconhecerem e legitimarem seu campo de atuação naquela cidade.

Embora as ideias médico-higienistas terem sido o grande impulsionador da assistência à infância pobre no Maranhão é relevante assinalar que a ação desse grupo era, acima de tudo, assegurar e legitimar um campo científico naquela sociedade. A infância pobre e suas necessidades, apesar de se constituírem um campo real para a assistência, não se configurava realmente como uma prioridade social e sim a ascensão de um campo.

As práticas realizadas no Instituto de Assistência à Infância através dos serviços médicos oferecidos às crianças pobres, consolidou o significado das representações do saber médico naquela sociedade, pois foi através da criação e fundação do Instituto de Assistência à Infância do Maranhão que 
esse saber se tornou imprescindível ao sucesso do projeto republicano naquela capital dando início a uma perspectiva política de ação sócio-educativa através da assistência à criança pobre.

Assim podemos dizer, por meio desse estudo, que foi a partir das ações do campo médico que oficialmente, no período republicano, se inicia uma prática de assistência com a criança, sobretudo, pobre no maranhão.

\section{REFERÊNCIAS}

Beghin, Nathalie. (2005). A filantropia empresarial: nem caridade e nem direito. São Paulo: Cortez.

Chartier, Roger. (1990). A História cultural: entre práticas e representações. Rio de Janeiro: Bertrand Brasil.

Dicionário da Língua Portuguesa. Lisboa: Texto editores Ltda. (2005). p. 1546. (Coleção completa de dicionários e auxiliares de línguas).

Dicionário da Língua Portuguesa: etimológico, prosódico e ortográfico (1927). 24. ed. Rio de Janeiro: Livraria Francisco Alves; Paris-Lisboa: Livrarias Aillaund e Bertrand..

Fernandes, Rogério; Vidigal, Luis (Coord.). (2005). Infantia et Pueritia. Santarém: Escola Superior de Educação de Santarém.

Ferreira, Aurélio Buarque de Holanda (1988). Dicionário Aurélio Básico da Língua Portuguesa. Rio de Janeiro: Nova Fronteira. p. 214

KuhImann Júnior, Moysés (1998). Infância, história e educação. In: Kuhlmann Júnior, Moysés. Infância e educação infantil: uma abordagem histórica. Porto Alegre: Mediação. p. $15-42$.

Meireles, M. M. ( 1994). Dez estudos históricos. São Luís: ALUMAR.

Michaelis (2002). Dicionário da Língua Portuguesa. São Paulo: Melhoramentos. p. 868.

Moncorvo Filho, Arthur (1914). Em torno do berço. Rio de Janeiro: Conferência Médico-Social.

Moncorvo Filho, Arthur (1926). Histórico da Proteção á infância no Brasil: 1500-1922. Rio de Janeiro: Empreza Gráphica Editora - Paulo, Pongetti \& Cia.

Lima, Olavo Correia (1951). História da Assistência à Infância no Maranhão. Revista do Instituto Histórico-Geográfico do Maranhão, ano 28. n. 3, ago.

Lisboa, João Francisco (1864). Obras de João Francisco Lisboa.

Rizzini, Irma (1993). História da Assistência à Infância no Brasil: uma análise de sua construção. Rio de Janeiro: Editora da Universidade Santa Úrsula. 